\title{
Guangdong Province: Trade Liberalization and HIV
}

\author{
Peng Lin, Yan Li, and Jonas Tillman
}

\begin{abstract}
The Guangdong experience is interesting as a case study, given its role as an economic hub, having attracted both domestic migrant workers, as well as people from abroad ever since the economic reforms of the late 1970s. The first Special Economic Zones were set up in Guangdong, due to its proximity to Hong Kong, most famously in the city of Shenzhen. The region has a prospering manufacturing industry, where both labor-intensive manufacturing products, as well as high-end technology products, are produced and assembled. Trade liberalization and rapid economic growth have also created a booming commercial sex industry and a situation where many economically-marginalized workers are migrating to the region. Here, we document the development of Guangdong's HIV epidemic, which has grown dramatically from 1997 to 2017, and we describe epidemic response efforts in Guangdong over the same period.
\end{abstract}

\subsection{Introduction}

Guangdong province is located in southern Mainland China and borders Fujian province to the northeast, Jiangxi and Hunan provinces to the north, Guangxi Zhuang Autonomous Region (hereafter Guangxi) to the west, and Hong Kong and Macau Special Administrative Regions (SARs) to the south.

Guangdong is the most populous province in China. The permanent population was estimated at nearly 112 million at the end of 2017 (8.0\% of the total population

P. Lin $(\bowtie) \cdot Y$. Li

Guangdong CDC, Guangzhou, China

J. Tillman

NCAIDS, China CDC, Beijing, China 
of China), including 86.4 million with local residence permits (known as hukou). In 2017, a majority of Guangdong's population was between the ages of 15 and 64 years of age $(74.2 \%)$ and resided in urban areas $(69.9 \%$; Statistics Bureau of Guangdong Province 2017).

Commonly referred to as the "Southern Gate of China," Guangdong has been an important hub for foreign trade for a long time, with the city of Canton (now named Guangzhou) having been the only port that allowed European trade as early as 1760 (Spence 1990). Since the adoption of the "Opening Up and Reform" policy of 1978, three special economic zones, Shenzhen, Zhuhai, and Shantou, have been established in Guangdong. Shenzhen was the first such zone to be created in the People's Republic of China, and also the most well-known. It underwent an incredible amount of economic development due to special economic policies (such as tax benefits), its proximity to Hong Kong, a significant amount of foreign direct investment (FDI), and the almost unlimited availability of temporary and cheap labor (Liang 1999). Guangdong was the province with the highest aggregated gross domestic product (GDP) in China, accounting for $10.9 \%$ of China's total GDP in 2017. The disposable annual per capita income in 2017 was 40,975 RMB for urban residents and slightly more than one-third of that for rural residents (Statistics Bureau of Guangdong Province 2017).

This chapter is meant to be an overview of China's HIV epidemic specific to Guangdong province, covering the epidemiology of HIV in the region up to 2017, the way that economic incentives have affected the risk behavior of certain groups, and the types of HIV interventions that have been put in place.

\subsection{The HIV Epidemic in Guangdong}

\subsubsection{Overview of the HIV Epidemic in Guangdong}

The first case of HIV infection in Guangdong province, an Argentinian national who was diagnosed with AIDS, was reported in 1986. Three similar cases of imported infections-HIV-positive foreigners entering the country-were identified between 1986 and 1989. The first case of HIV infection in a Guangdong resident was reported in 1990. This individual had just returned from abroad and presumably acquired the infection overseas. From 1990 to 1994, a further 112 cases of imported infections, mostly Guangdong residents, were reported and by the end of this period, 12 of Guangdong's 21 prefectures had at least one HIV case. The most commonly identified transmission route identified by these people living with HIV (PLWH) was heterosexual contact.

The first locally-acquired HIV infections in Guangdong began to be identified in 1995. Although a majority of newly-diagnosed cases of HIV infection continued to report heterosexual contact as their infection route, Guangdong's first HIV infection reported as acquired via drug injection had been identified by 1996. From 1997 to 2007, the HIV epidemic in Guangdong province was in a rapid growth phase, which was characterized by an explosion in HIV prevalence among people who inject drugs (PWID). Although infection via heterosexual contact continued to occur 
during this period as well, it was not until 2008, when it regained its position as the most common HIV transmission route in Guangdong. Also in 1998, the first cases of infection via homosexual contact emerged, and thereafter, HIV prevalence began to increase among men who have sex with men (MSM). For the first time, in 2012, the male-male sexual contact route had surpassed the injecting drug use route in terms of transmission event frequency. By the end of 2017, a cumulative 81,641 cases of HIV infection had been reported in Guangdong, among whom 33,993 had progressed to AIDS, and 21,006 had died.

In taking a closer look at the characteristics of the PLWH who were diagnosed in Guangdong province in the two decades between 1997 and 2017, several important observations can be made. Among these 81,586 HIV/AIDS cases, a majority were male $(81 \%)$, and most were either in their twenties or thirties $(60 \%$; Table 34.1$)$. The main routes of transmission were heterosexual contact (55\%) and injection drug use $(21 \%)$. Although, a majority were residents $(59 \%)$ and a relatively large proportion were not legal permanent residents $(41 \%)$. Finally, the most densely populated central region of Guangdong had the largest proportion of HIV cases (71\%), compared to the western region (20\%) and the eastern region (9\%; Fig. 34.1).

Table 34.1 Characteristics of PLWH diagnosed in Guangdong province from 1997 to 2017 and in successive 5-year periods

\begin{tabular}{|c|c|c|c|c|c|}
\hline Characteristics & $\begin{array}{l}1997-2017 \\
N(\%)\end{array}$ & $\begin{array}{l}1997-2002 \\
N(\%)\end{array}$ & $\begin{array}{l}2003-2007 \\
N(\%)\end{array}$ & $\begin{array}{l}2008-2012 \\
N(\%)\end{array}$ & $\begin{array}{l}2013-2017 \\
N(\%)\end{array}$ \\
\hline Overall & $81,586(100)$ & $1528(100)$ & $9902(100)$ & $24,583(100)$ & $45,573(100)$ \\
\hline \multicolumn{6}{|l|}{ Gender } \\
\hline Male & $66,098(81.0)$ & $1391(91.0)$ & $8276(83.6)$ & $18,596(75.6)$ & 37,835 (83.0) \\
\hline Female & $15,488(19.0)$ & $137(9.0)$ & $1626(16.4)$ & 5987 (24.4) & $7738(17.0)$ \\
\hline \multicolumn{6}{|c|}{ Age at diagnosis, years } \\
\hline$<15$ & $525(0.6)$ & $7(0.5)$ & $68(0.7)$ & $248(1.0)$ & $199(0.4)$ \\
\hline $15-19$ & $1924(2.4)$ & $43(2.8)$ & 113(1.1) & $423(1.7)$ & $1343(2.9)$ \\
\hline $20-29$ & $23,494(28.8)$ & $794(52.0)$ & $3445(34.8)$ & $6476(26.3)$ & $12,754(28.0)$ \\
\hline $30-39$ & $25,061(30.7)$ & $580(38.0)$ & $4553(46.0)$ & $8800(35.8)$ & $11,117(24.4)$ \\
\hline $40-49$ & $14,777(18.1)$ & $76(5.0)$ & $1128(11.4)$ & $4423(18.0)$ & $9147(20.1)$ \\
\hline$\geq 50$ & $15,853(19.4)$ & $25(1.6)$ & $592(6.0)$ & $4213(17.1)$ & $11,013(24.2)$ \\
\hline Unknown & $7(<0.1)$ & $3(0.2)$ & $3(<0.1)$ & $0(0.0)$ & $0(0.0)$ \\
\hline \multicolumn{6}{|l|}{ Transmission route } \\
\hline $\begin{array}{l}\text { Heterosexual } \\
\text { contact }\end{array}$ & $44,899(55.0)$ & $134(8.8)$ & $2286(23.1)$ & $13,860(56.4)$ & $28,584(62.7)$ \\
\hline Injection drug use & $16,711(20.5)$ & $1300(85.1)$ & $6615(66.8)$ & $6232(25.4)$ & $2559(5.6)$ \\
\hline $\begin{array}{l}\text { Homosexual } \\
\text { contact }\end{array}$ & $17,306(21.2)$ & $5(0.3)$ & $106(1.1)$ & $3391(13.8)$ & $13,804(30.3)$ \\
\hline Blood products & $401(0.5)$ & $24(1.6)$ & $103(1.0)$ & $267(1.1)$ & $2(<0.1)$ \\
\hline Mother-to-child & $441(0.5)$ & $2(0.1)$ & $53(0.5)$ & $227(0.9)$ & $159(0.3)$ \\
\hline Not classified & $1883(2.3)$ & $63(4.1)$ & $739(7.5)$ & $606(2.5)$ & $465(1.0)$ \\
\hline \multicolumn{6}{|l|}{ Guangdong residency } \\
\hline Resident & $47,900(58.7)$ & $1325(86.7)$ & $6996(70.7)$ & $14,959(60.9)$ & 24,582 (52.9) \\
\hline Non-resident & $33,293(40.8)$ & $187(12.2)$ & $2475(25.0)$ & $9624(39.1)$ & 20,991 (46.1) \\
\hline Unknown & $448(0.5)$ & $16(1.0)$ & $431(4.4)$ & $0(0.0)$ & $0(0.0)$ \\
\hline \multicolumn{6}{|l|}{ Region in Guangdong } \\
\hline Central & $57,606(70.6)$ & 1358 (88.9) & 7057 (71.3) & $16,918(68.8)$ & $32,242(70.7)$ \\
\hline West & $16,426(20.1)$ & $115(7.5)$ & $2354(23.8)$ & $5632(22.9)$ & $8324(18.3)$ \\
\hline East & 7609 (9.3) & $55(3.6)$ & $491(5.0)$ & $2033(8.3)$ & $5007(11.0)$ \\
\hline
\end{tabular}




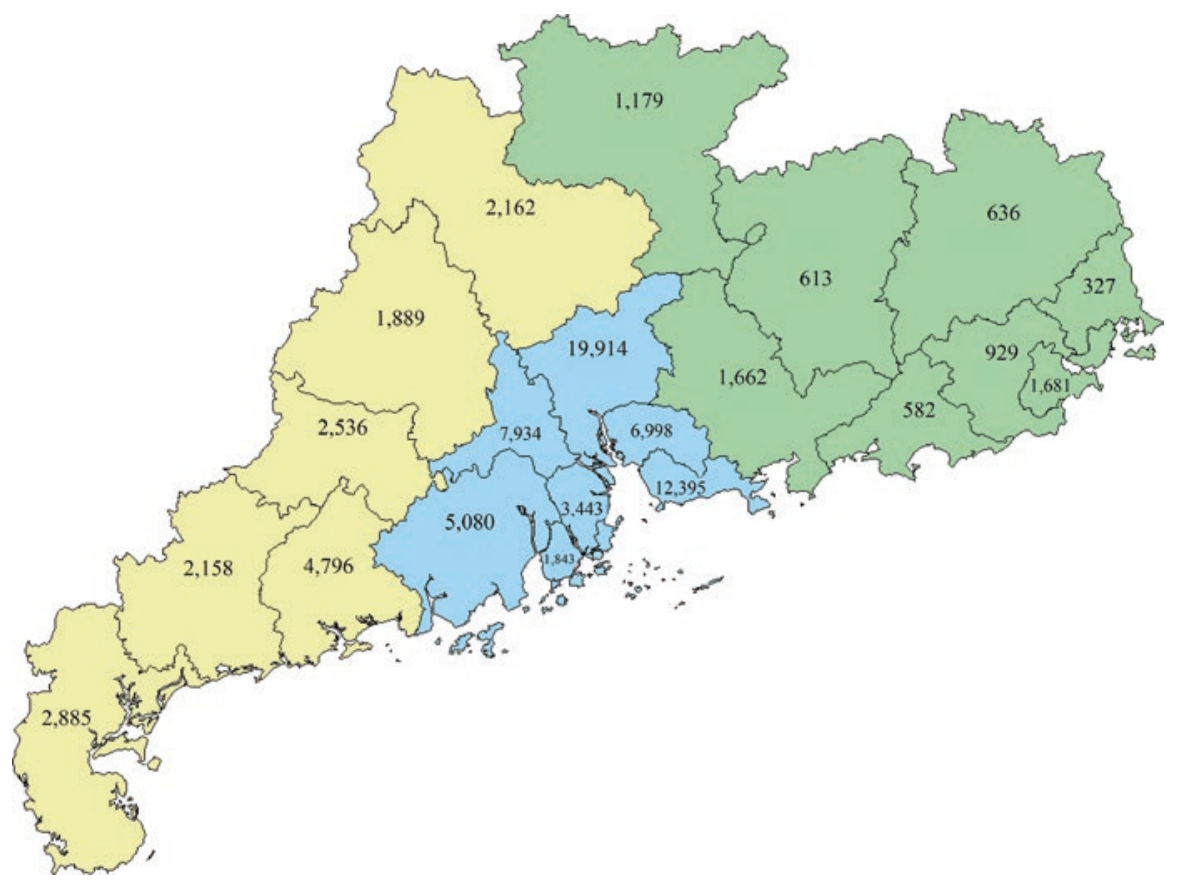

Fig. 34.1 Map illustrating the central (blue), western (yellow), eastern (green) geographical regions within Guangdong province as well as the geographical distribution of the total, cumulative numbers of HIV/AIDS cases reported across the three regions over the period from 1997 to 2017

When the 1997 to 2017 time period is divided into smaller spans of years, some trends are observable. For example, the age profile trended older-half of all PLWH diagnosed between 1997 and 2002 were in their twenties (52\%), but only roughly one-quarter of PLWH diagnosed between 2013 and 2017 were (28\%), whereas less $2 \%$ were in their fifties between 1997 and 2002 and 24\% were in their fifties between 2013 and 2017. Similarly, the proportion of PLWH who were non-residents increased over time from 12\% in the 1997 to 2002 period to $46 \%$ in the 2013 to 2017 period (Table 34.1).

The total numbers of cases identified increased roughly 30-fold from the 1997 to 2002 period $(n=1528)$ to the 2013 to 2017 period $(n=45,573)$. In the earlier years, the vast majority of PLWH were men, but prevalence gradually increases among women over time (Table 34.1 and Fig. 34.2). The dramatic increase in HIV cases among men between 2003 and 2005 may be, at least in part, due to HIV testing campaigns that were conducted in detention centers during this time. The dominant transmission route shifted from injection drug use (85\%) in the 1997-2002 period 
to heterosexual contact (56\%) in the 2013-2017 period, with other transmission routes emerging then as well-homosexual contact (30\%), and mother-to-child transmission (0.3\%; Table 34.1 and Fig. 34.3).

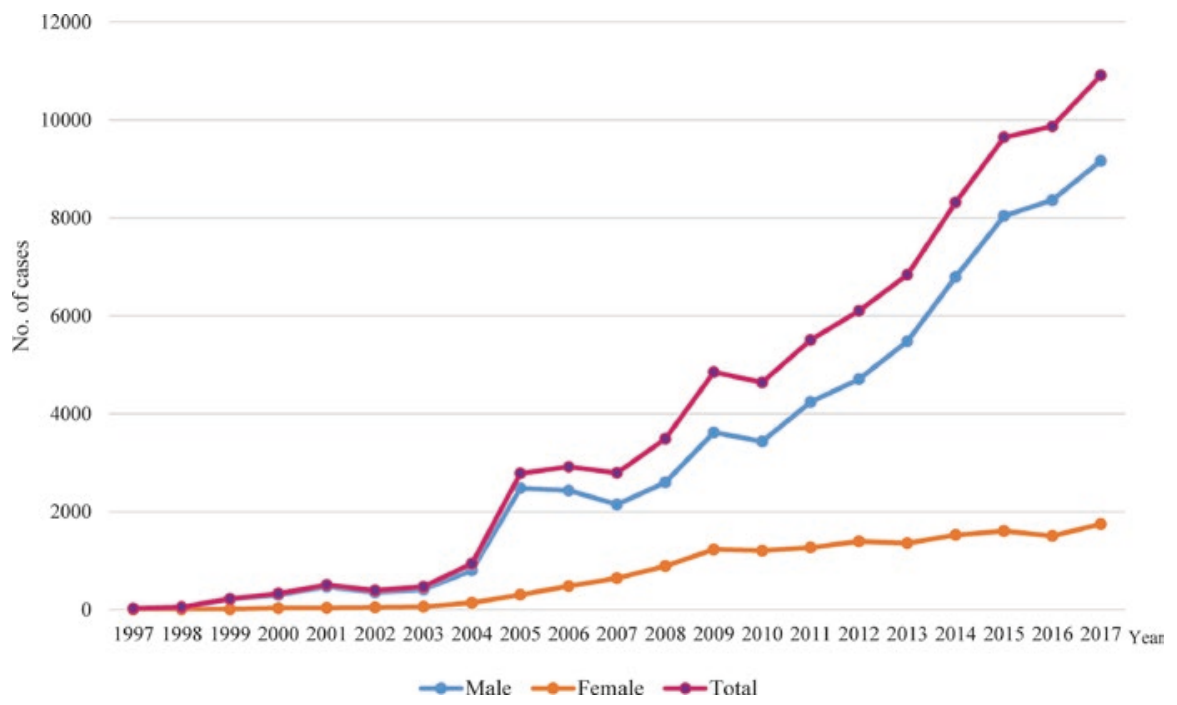

Fig. 34.2 Number of HIV cases reported in Guangdong each year from 1997 to 2017 overall and stratified by sex

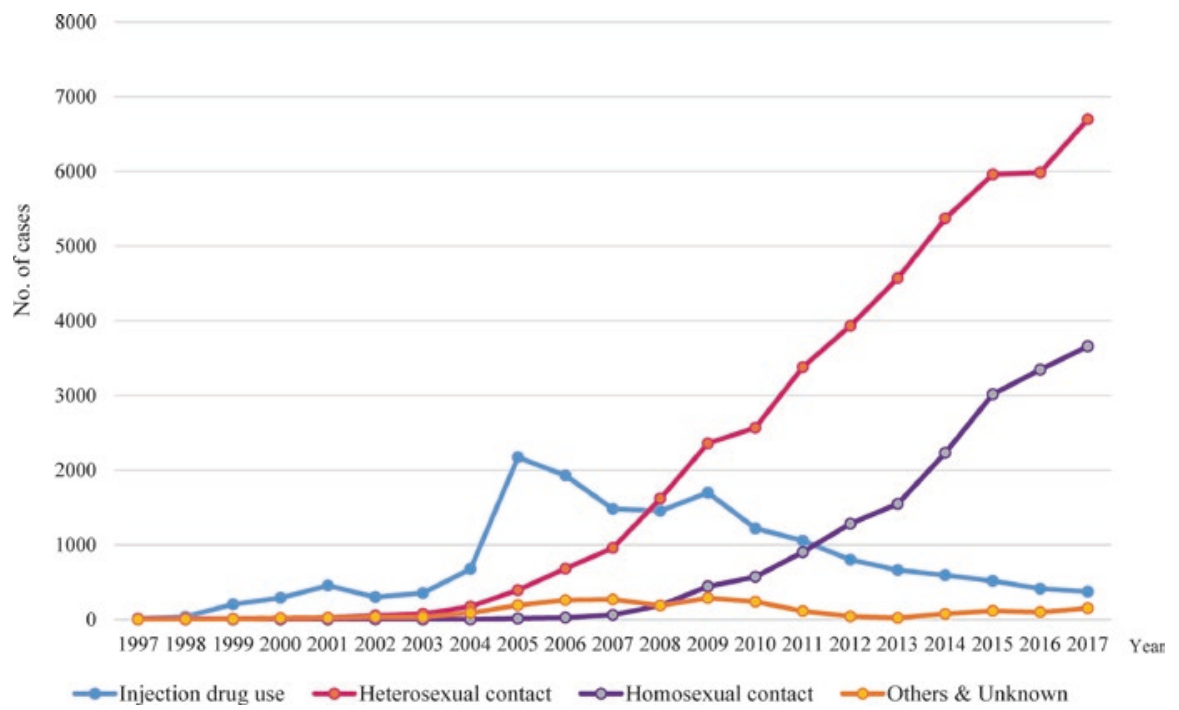

Fig. 34.3 Number of HIV cases reported in Guangdong each year from 1997 to 2017 by transmission route 


\subsubsection{Overview of the HIV Response}

\subsubsection{Case Reporting}

A mandatory HIV reporting system has been in place in China since 1985, whereby all cases of HIV infection are required to be reported to the local Center for Disease Control and Prevention (CDC) by the medical facility making the diagnosis. Case reports were escalated from local to provincial, and then ultimately to national level CDC personnel, using a paper card system. In 2008, a new, real-time, web-based data system, which contained case reporting, was launched and replaced the earlier paper-based system. This new data system is called the National HIV/AIDS Comprehensive Response Information Management System (CRIMS). Guangdong participated in the development and pilot testing of this new system (see Chap. 24 for more information).

\subsubsection{Funding}

In 2003, the Chinese government officially recognized its HIV epidemic and launched its "Four Frees One Care" policy, which marked a major turning point in China's HIV response (see Chaps. 1 and 25 for more information).

Later that same year, the provincial government of Guangdong organized the first provincial-level funds devoted to HIV control and prevention. These funds amounted to ten million RMB annually and were later increased to 30 million RMB annually beginning in 2011. The primary purpose was to ensure sufficient financial backing for the strengthening of HIV surveillance in the region. In 2004, the HIV Prevention and Control Committee of Guangdong Province was established. The committee included more than 30 government departments and covered several of the prefectures in Guangdong that, at that time, had high HIV prevalence.

\subsubsection{Sentinel Surveillance}

China's nationwide sentinel surveillance system was launched in 1992 (see Chap. 2 for more information).

In Guangdong province, specifically, sentinel surveillance began a few years later in 1995 and by 1996 three sites were operating, one for PWID, one for female sex workers (FSW), and one for attendees of sexually-transmitted infection (STI) clinics. This network grew over the years such that by the end of 2017 , there were 119 sentinel surveillance sites in Guangdong alone, covering several different key, high-risk populations (Table 34.2).

\subsubsection{Testing}

HIV voluntary counseling and testing (VCT) services have been provided at all levels of the CDC system in Guangdong (provincial, prefectural, and county) and in some other medical facilities (e.g., hospitals). Provider-initiated testing and counseling (PITC) has also been scaled up in various types of medical facilities. Furthermore, some epidemiologic surveys and studies have been conducted in the province. To keep up with the demand for HIV testing services, the number of HIV testing laboratories has increased rapidly across health and public health facilities at 


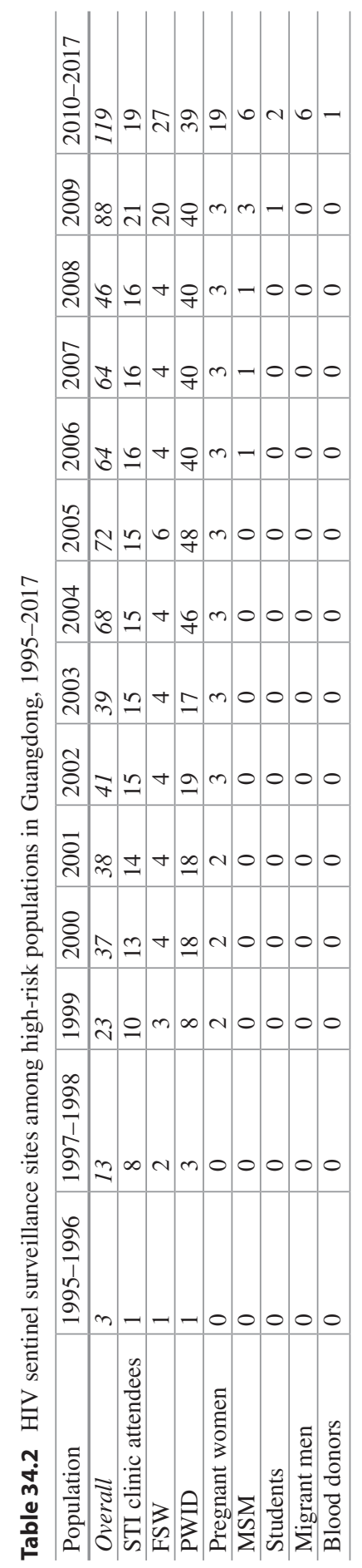


provincial, prefectural, and county levels. In 2017, Guangdong province had one provincial-level HIV confirmatory testing center, 37 HIV confirmatory testing laboratories, and more than $1814 \mathrm{HIV}$ screening laboratories and rapid testing sites. In 2017 alone, more than 13 million HIV tests were conducted in Guangdong province (see Chaps. 5 and 12 for more information).

\subsubsection{Treatment}

Although free antiretroviral therapy (ART) for PLWH was launched in 2003 in Guangdong province, only one Guangzhou patient received free ART that year. In 2004, 65 AIDS patients in Guangdong received free ART. ART was only available in three Guangdong prefectures in 2004 but had expanded to all 21 prefectures by 2013. As of the end of 2017, a cumulative 53,639 PLWH in Guangdong had received free ART, with 44,190 still in treatment (see Chap. 13 for more information).

\subsection{HIV and High-Risk Groups}

\subsubsection{Drug Users}

\subsubsection{Characteristics of PLWH Who Are Drug Users}

Guangdong province has the highest number of registered drug users in China. In 2017, there were more than 677,255 drug users, more than $26 \%$ of the national total. From 1997 to 2017, a total of 16,134 HIV cases in Guangdong province were reported to have been acquired via injection drug use (Table 34.3).

Table 34.3 Characteristics of HIV-positive PWID diagnosed in Guangdong province from 1997 to 2017 and in successive 5-year periods

\begin{tabular}{|c|c|c|c|c|c|}
\hline Characteristics & $\begin{array}{l}1997-2017 \\
N(\%)\end{array}$ & $\begin{array}{l}1997-2002 \\
N(\%)\end{array}$ & $\begin{array}{l}2003-2007 \\
N(\%)\end{array}$ & $\begin{array}{l}2008-2012 \\
N(\%)\end{array}$ & $\begin{array}{l}2013-2017 \\
N(\%)\end{array}$ \\
\hline Overall & $16,134(100)$ & $1296(100)$ & $6521(100)$ & $5920(100)$ & $2397(100)$ \\
\hline \multicolumn{6}{|l|}{ Gender } \\
\hline Male & $15,182(94.1)$ & $1230(94.9)$ & 6187 (94.9) & 5557 (93.9) & $2208(92.1)$ \\
\hline Female & $952(5.9)$ & $66(5.1)$ & $334(5.1)$ & $363(6.1)$ & $189(7.9)$ \\
\hline \multicolumn{6}{|c|}{ Age at diagnosis, years } \\
\hline$<15$ & $5(<0.1)$ & $3(0.2)$ & $1(<0.1)$ & $1(<0.1)$ & $0(0.0)$ \\
\hline $15-19$ & $179(1.1)$ & $39(3.0)$ & $52(0.8)$ & $57(1.0)$ & $31(1.3)$ \\
\hline $20-29$ & $4700(29.1)$ & $700(54.0)$ & $2348(36.0)$ & $1264(21.4)$ & $388(16.2)$ \\
\hline $30-39$ & $7960(49.3)$ & $501(38.7)$ & $3358(51.5)$ & $3205(54.1)$ & $896(37.4)$ \\
\hline $40-49$ & $2852(17.7)$ & $47(3.6)$ & $696(10.7)$ & $1225(20.7)$ & $884(36.9)$ \\
\hline$\geq 50$ & $439(2.7)$ & $5(0.4)$ & $66(1.0)$ & $168(2.8)$ & $198(8.3)$ \\
\hline Unknown & $1(<0.1)$ & $1(0.1)$ & $0(0.0)$ & $0(0.0)$ & $0(0.0)$ \\
\hline \multicolumn{6}{|c|}{ Guangdong residency } \\
\hline Resident & $11,574(71.7)$ & $1156(89.2)$ & $5011(76.8)$ & $4001(67.6)$ & $1406(58.7)$ \\
\hline Non-resident & $4543(28.2)$ & $125(9.6)$ & $1508(23.1)$ & $1919(32.4)$ & $991(41.3)$ \\
\hline Unknown & $17(0.1)$ & $15(1.2)$ & $2(<0.1)$ & $0(0.0)$ & $0(0.0)$ \\
\hline \multicolumn{6}{|l|}{ Region } \\
\hline Central & $11,261(69.8)$ & $1183(91.3)$ & $4619(70.8)$ & $3818(64.5)$ & $1641(68.5)$ \\
\hline West & 4134 (25.6) & $97(7.5)$ & $1675(25.7)$ & $1790(30.2)$ & $572(23.9)$ \\
\hline East & 739 (4.6) & $16(1.2)$ & $227(3.5)$ & $312(5.3)$ & $184(7.7)$ \\
\hline
\end{tabular}




$$
2500
$$

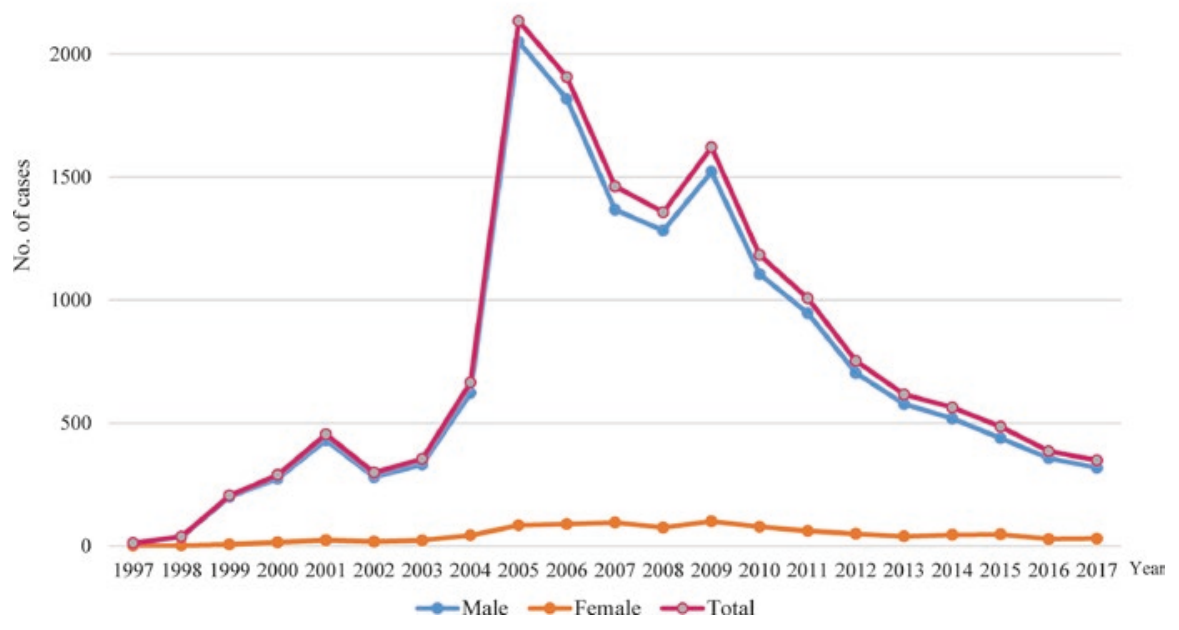

Fig. 34.4 Number of HIV cases among PWID reported annually in Guangdong province from 1997 to 2017 overall and stratified by sex

Overall, a majority of HIV-infected PWID in Guangdong from 1997 to 2017 were male (94\%), 30-39 years of age (49\%), legal permanent residents of Guangdong province $(72 \%)$, and were diagnosed in the densely-populated central region of the province (70\%). Changes over time among the PWID who were found to be HIV-positive mirrored that of the broader population of PLWH in Guangdonglarger proportions of the population were older, non-residents, and diagnosed in the western region in more recent years. Also, although overall a much greater number of HIV-infected PWID were male, a slow increase in HIV cases among female PWID was observed in the early 2000s, and then a slow decline in more recent years (Table 34.3 and Fig. 34.4).

\subsubsection{Sentinel Surveillance Among Drug Users}

The first HIV sentinel surveillance site among drug users in Guangdong province was launched at a detoxification center in 1995 . The number of sites grew over time to a total of 38 sites by the end of 2017. In line with national guidelines, a convenience sampling method has been used to conduct serological surveys and high-risk behavioral surveys among drug users newly admitted to Guangdong's detoxification centers on an annual or biannual basis. Target sample size has generally been 200-400 individuals per site, although sample sizes sometimes, at some sites, surpassed 400.

Sentinel surveillance data from sites targeting drug users in Guangdong province from 2000 to 2017 indicate that peak HIV prevalence occurred between 2003 and 2005. HIV prevalence among drug users has since remained relatively low-estimated to be less than $2 \%$ (Fig. 34.5). 


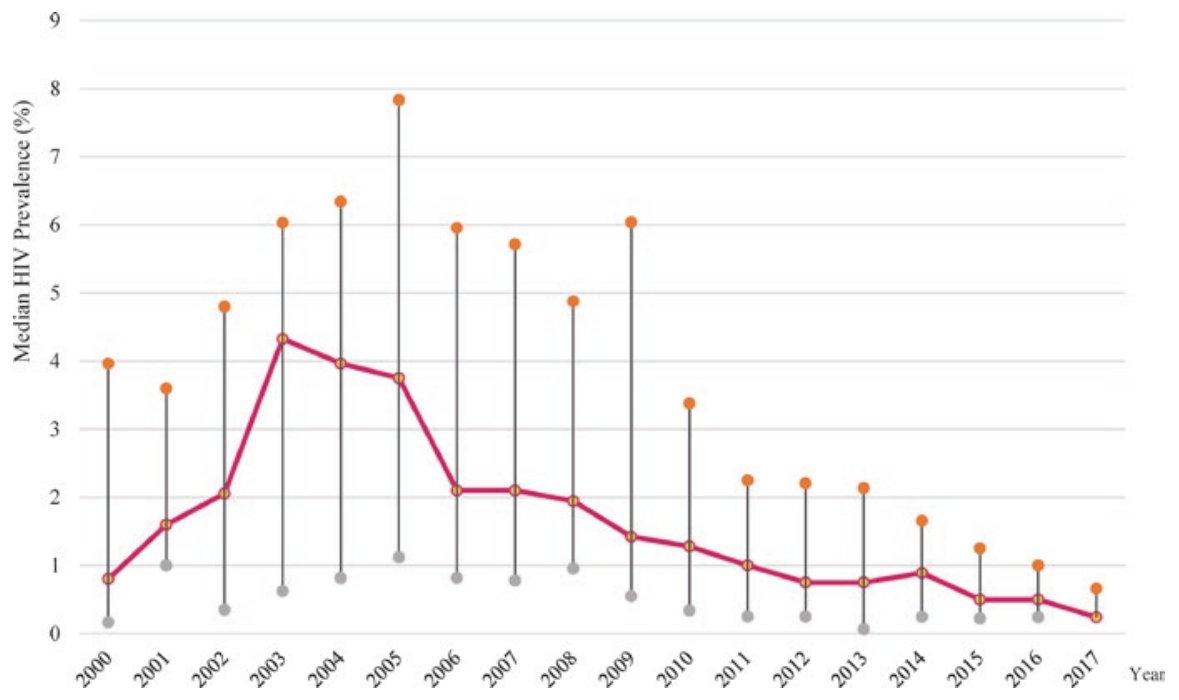

Fig. 34.5 Median HIV prevalence at sentinel surveillance sites targeting drug users in Guangdong province from 2000 to 2017 . Vertical bars represent the inter-quartile range

However, since all the sentinel surveillance sites for drug users in Guangdong province have been in detention centers, samples may not be generalizable to the broader drug using population of Guangdong. Results from a 2008 study in Guangdong provide evidence that the HIV prevalence among community-based drug users (i.e., not in detoxification centers) was significantly higher (8\%) compared to those in detention centers (4\%; Lin et al. 2013).

\subsubsection{Harm Reduction Programs for Drug Users}

To reduce the transmission of HIV through unsafe drug injection practices, both methadone maintenance treatment (MMT) and needle and syringe exchange programs (NSEP) were established. As a part of China's National MMT Program, the first MMT clinic in Guangdong province was established at the end of 2005 and began treating opioid users in 2006. By the end of 2017, the number of MMT clinics in Guangdong had increased to 66, and the total cumulative number of clients treated at these clinics had reached nearly 36,000 (see Chap. 9 for more information).

China's National NSEP was launched in 2001, and the first two sites in Guangdong province were opened in 2005. A total of 106 sites have since been established as of the end of 2017 across 16 counties in six prefectures. In 2017, Guangdong province's NSEP sites had covered an average of 19,613 PWID every month and nearly 350,000 syringes had been distributed and almost 290,000 had been returned (see Chap. 10 for more information). 


\subsubsection{Female Sex Workers (FSW)}

\subsubsection{Resurgence of the Sex Industry}

The Chinese Government crackdown on so-called "social evils" in 1949 led to a dramatic decline in the sex trade, with no official records of commercial sex workers in the decades following. However, Guangdong province was the first region to adopt market economy-oriented reforms and liberalized trade policies, which drew in a large number of people seeking to conduct business in the region. Thus, Guangdong has been a hub of domestic and foreign trade and a magnet for domestic migration as well as foreign immigration. These conditions made Guangdong ripe for the development of active sex trade.

Since the late 1970s, the number of individuals involved in commercial sex has increased rapidly. The earliest record of commercial sex work in Guangdong province after the Mao Era was the arrest records of 49 sex workers and their clients by police in 1979. Today, Guangdong is estimated to have the largest number of FSW in China. Dongguan, a key industrial city located in the Pearl River Delta, is known as the "factory of the world," but has also earned a reputation for being the "sex capital of China."

Since commercial sex remains illegal in China, albeit tolerated to some extent on local levels, venues, where transactions and agreements are made, tend to be hidden, and prostitution is often conducted indirectly in the course of other business at clubs, bars, tea shops, beauty salons, and hotels. The number of five-star hotels in Dongguan ranks third in the country after Beijing and Shanghai, and there are more than 1000 licensed hotels in the city, many which facilitate prostitution.

A 2005 study conducted in one Guangdong county estimated that FSW made up somewhere between $0.7 \%$ and $1.0 \%$ of the entire adult female population, and between $2.8 \%$ to $3.7 \%$ of the adult female population in the urban areas of the county (Li et al. 2006). Surveys in the early-2000s indicate that about one-third of men returning to Hong Kong from Mainland China reported having had sex with FSW in China in the last 6 months, one-third of whom did not use condoms (Lau and Thomas 2001). In a recent study conducted in two cities in Guangdong (Dongguan and Foshan), only 49\% of the clients of FSW reported using condoms during sexual contact with FSW (Zhao et al. 2018).

\subsubsection{Sentinel Surveillance Among FSW}

The first HIV sentinel surveillance site for FSW in Guangdong province was established in 1995. By 2012, the number of sites had increased to 27. At first, these were associated with detention centers, and thus, like sites for drug users, only examined the incarcerated portion of this key population. Over time, surveillance was transitioned to more community-based sites, and starting in 2010, all sentinel surveillance sites targeting the FSW population in Guangdong were community-based.

In 2017, FSW with HIV infection were found at 8 of the 27 sites. The highest HIV prevalence observed at a single site was $1.5 \%$. However, syphilis infection was 
Table 34.4 HIV prevalence among FSW in Guangdong overall, and at the original three sentinel surveillance sites in Guangdong from 1997 to 2017

\begin{tabular}{|c|c|c|c|c|c|c|}
\hline \multirow[b]{2}{*}{ Year } & \multicolumn{3}{|c|}{ Guangdong province overall } & \multicolumn{3}{|c|}{ HIV prevalence (\%) } \\
\hline & $\begin{array}{l}\text { Total tested } \\
N\end{array}$ & $\begin{array}{l}\text { HIV-positive } \\
N\end{array}$ & $\begin{array}{l}\text { HIV } \\
\text { prevalence } \\
\%\end{array}$ & $\begin{array}{l}\text { Guangzhou } \\
\text { only }\end{array}$ & $\begin{array}{l}\text { Shenzhen } \\
\text { only }\end{array}$ & $\begin{array}{l}\text { Zhuhai } \\
\text { only }\end{array}$ \\
\hline 1997 & 1823 & 0 & 0 & 0 & 0 & 0 \\
\hline 1998 & 1150 & 2 & 0.17 & 0.31 & 0 & 0 \\
\hline 1999 & 1600 & 4 & 0.25 & 0.78 & 0 & 0 \\
\hline 2000 & 1199 & 13 & 1.08 & 2.21 & 0 & 0 \\
\hline 2001 & 1123 & 12 & 1.07 & 2.27 & 0 & 0 \\
\hline 2002 & 1262 & 19 & 1.51 & 1.60 & 1.74 & 0.82 \\
\hline 2003 & 1273 & 17 & 1.34 & 1.68 & 0.58 & 1.56 \\
\hline 2004 & 1229 & 5 & 0.41 & 0.94 & 0 & 0.30 \\
\hline 2005 & 507 & 2 & 0.39 & 0 & 0 & 0.72 \\
\hline 2006 & 626 & 5 & 0.80 & 1.66 & 0 & 2.25 \\
\hline 2007 & 651 & 2 & 0.31 & 0 & 0 & 1.68 \\
\hline 2008 & 607 & 1 & 0.16 & 0 & 0 & 1.06 \\
\hline 2009 & 5646 & 10 & 0.18 & 0.20 & 0 & 0 \\
\hline 2010 & 9537 & 7 & 0.07 & 0.12 & 0.23 & 0.25 \\
\hline 2011 & 10,899 & 13 & 0.12 & 0 & 0 & 0.25 \\
\hline 2012 & 11,153 & 11 & 0.1 & 0 & 0 & 0 \\
\hline 2013 & 11,505 & 5 & 0.04 & 0.12 & 0 & 0 \\
\hline 2014 & 10,186 & 5 & 0.05 & $<0.01$ & $<0.01$ & $<0.01$ \\
\hline 2015 & 11,245 & 6 & 0.05 & 0.12 & $<0.01$ & 0.25 \\
\hline 2016 & 11,404 & 10 & 0.09 & 0.12 & 0 & 0 \\
\hline 2017 & 11,275 & 19 & 0.17 & $<0.01$ & $<0.01$ & $<0.01$ \\
\hline
\end{tabular}

diagnosed among FSW at 26 of 27 sites, and a syphilis prevalence ranging from $0.0 \%$ to $7.2 \%$ was found. Median syphilis prevalence among FSW tested at sentinel surveillance sites in 2017 was $0.9 \%$ (inter-quartile range [IQR]: 0.5-0.9\%).

In an attempt to exclude the possible effect of the increasing number of sentinel surveillance sites for FSW on changes in HIV prevalence over time, annual results from only the original three sites were tabulated (Table 34.4). The results show that the HIV prevalence has been at a stable, low level since 2008. One possible explanation for the higher prevalence estimates in 2007 and prior may be the differences between samples drawn from detention centers versus communities. In general, low-fee FSW in China face a higher risk of incarceration due to their relatively greater exposure- they are not conducting business from inside a venue and do not have the protection of a venue owner and other FSW. Furthermore, evidence indicates that low-fee FSW tend to have higher HIV prevalence due in large part to their reduced ability to negotiate condom use because of economic pressures and vulnerability to client violence. The higher HIV prevalence in earlier years when samples were taken from detention centers is therefore not surprising.

Research has supported the sentinel surveillance findings of low overall HIV prevalence among FSW in Guangdong. For example, in a study using respondentdriven sampling to recruit FSW in the community in Zhaoqing prefecture in 2006, zero of the 320 participants recruited were found to have HIV infection. However, 
the same study found the prevalence of syphilis, gonorrhea, and chlamydia to be high $(8.0 \%, 9.5 \%$, and $3.9 \%$, respectively), indicating a high frequency of risky sexual behavior in the sample (Li et al. 2010). Another study conducted in Jiangmen showed that the HIV prevalence among FSW in high-, middle- and low-fee settings was $0.14 \%, 0.23 \%$, and $1.53 \%$, respectively (Zhang and Huang 2012). A study conducted among low- and mid-tier FSW found an HIV prevalence of $0.3 \%$, a syphilis prevalence of 5\%, and a herpes simplex 2 virus (HSV-2) prevalence of $31 \%(\mathrm{Fu}$ et al. 2014). In another study conducted in Guangzhou, no HIV infection was found among high- and mid-tier FSW sampled but found a $2.63 \%$ HIV prevalence among low-tier FSW participants (Li et al. 2016). This study also reported that street-based FSW tended to have lower levels of education, to be supporting their families, to charge less for their services, and to remain in the commercial sex industry for a longer time, compared to establishment-based FSW. Also, the proportion of low-fee FSW consistently using condoms with clients and with regular, non-commercial partners was lower than for the mid- and high-fee FSW. The prevalence of syphilis, gonorrhea, and chlamydia was also higher among street-based FSW (Li et al. 2012). Finally, a cross-sectional study conducted in three cities in Guangdong found an HIV prevalence of $0.6 \%$ among FSW (Shen et al. 2016) (see Chaps. 3 and 7 for more information).

\subsubsection{Harm Reduction for FSW}

To reduce the transmission of HIV through sexual contact, behavioral intervention programs, particularly condom use promotion programs, were conducted. In 2004, behavioral intervention groups had been established at all levels of the CDC system. Outreach and peer education programs were conducted among street-based and establishment-based FSW. Some of these programs were developed and run by CDC personnel and some by civil society organizations, both non-government organizations (NGOs) and community-based organizations (CBOs). In 2017, these programs covered an average of roughly 24,000 FSW per month, and a total of 83,319 FSW were tested for HIV in that year.

\subsubsection{Patients with Other Sexually-Transmitted Infections (STIs)}

\subsubsection{A Dramatic Increase in STI Incidence}

With the resurgence of the sex industry in China, STI prevalence has increased dramatically. Guangdong is one of the provinces with the highest rates of STIs in all of China. In 1995, the combined incidence of eight different sexually transmitted infections was over 128 cases per 100,000 residents, the highest incidence measured in any Chinese province (Gong et al. 2002). According to government statistics, the incidence of syphilis increased nearly every year from 1995 to 2010. The average year-over-year increase was an alarming 38\%. Syphilis incidence increased from 1.8 per 100,000 residents in 1995 to over 47 per 100,000 residents in 2010 (Tucker and Cohen 2011). From 1977 to 1993, the average annual incidence of gonorrhea was 34 diagnosed cases per 100,000 residents, ranking second highest in China at 


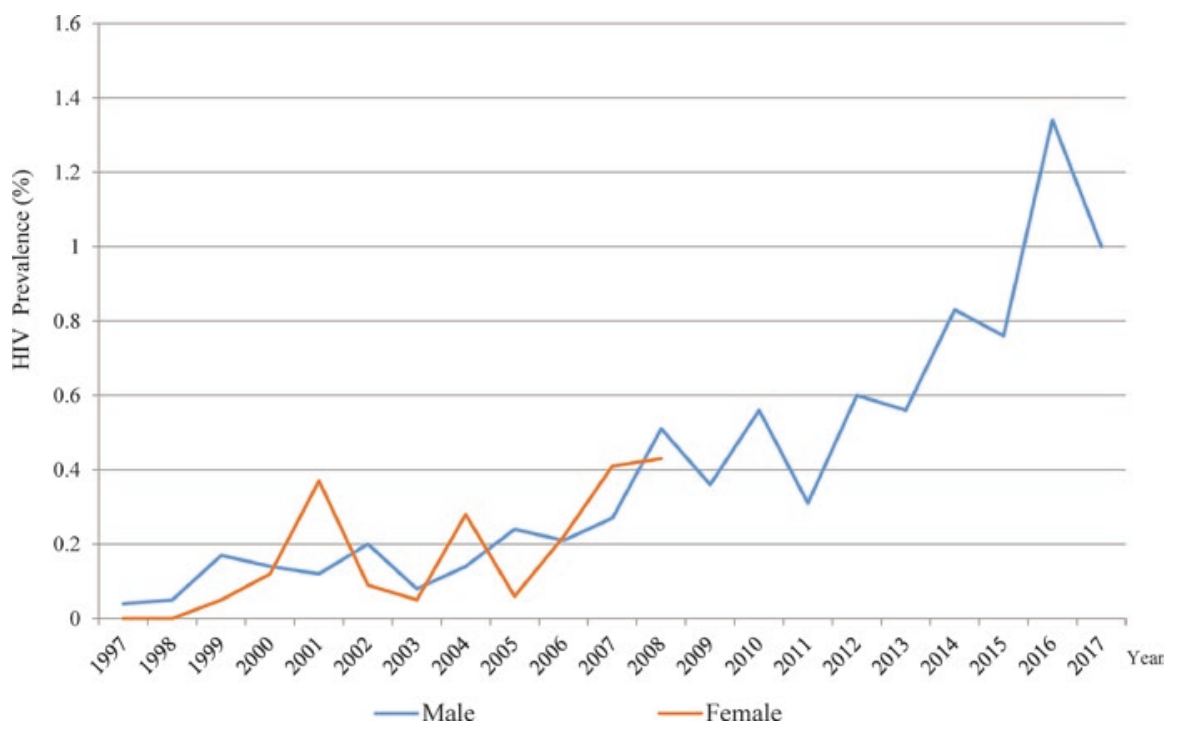

Fig. 34.6 Annual sentinel surveillance estimates of HIV prevalence among male and female STI clinic attendees in Guangdong province from 1997 to 2017

that time (Song et al. 1995). However, gonorrhea incidence has since decreased from 55 per 100,000 residents in 1995 to 19 per 100,000 residents in 2010 (Wang et al. 2013) (see Chap. 3 for more information).

\subsubsection{Sentinel Surveillance for STI Outpatients}

By 2012, HIV sentinel surveillance sites targeting STI clinic attendees had been set up in all 19 prefectural cities, except Heyuan and Shanwei. HIV prevalence based on sentinel surveillance data for this key population from 1997 to 2017 shows an overall upward trend among both males and females (Fig. 34.6), which may be a reflection of the generally high prevalence of high-risk sexual behavior among this group.

Several studies conducted among STI clinic outpatients in Guangdong have shown a similar increasing trend in HIV prevalence within this population. A survey of STI outpatients in Jiangmen found that HIV prevalence increased from $0 \%$ to $1.3 \%$ over the period from 2003 to 2007 (Tan et al. 2008). A survey of STI outpatients in Dongguan found that HIV prevalence increased from $0.5 \%$ to $3 \%$ over the period from 2010 to 2016 (Deng and Liu 2018). For the male subpopulation HIV prevalence increased gradually from $0.5 \%$ in 2008 to $2 \%$ in 2012 in the same area (Zhang et al. 2013). A study conducted in Shantou in eastern Guangdong found that HIV prevalence among STI outpatients had also increased from $0.04 \%$ in 2004 to $0.26 \%$ in 2011 (Fang et al. 2012). A cross-sectional study conducted in three cities in Guangdong reported HIV prevalence among male STI patients to be 3.3\% (Zhao et al. 2016). Finally, in a recent study in two Guangdong cities, prevalence of HIV among FSW STI clinic attendees was found to be over 4\% (Zhao et al. 2018) (see Chap. 3 for more information). 


\subsubsection{Harm Reduction for STI Clinic Attendees}

In an effort to reduce the transmission of HIV through sexual contact, behavioral intervention programs, including health education campaigns and condom use promotion programs, were conducted among STI clinic attendees. HIV PITC was also scaled up in STI clinics. The number of HIV tests provided to STI clinic attendees in Guangdong province increased from 69,930 in 2011 to 380,642 in 2017 (see Chaps. 11 and 12 for more information).

\subsubsection{Men Who Have Sex with Men (MSM)}

\subsubsection{HIV on the Rise Among MSM}

Although the first case of HIV identified in the MSM community in Guangdong was reported in 1998, HIV prevalence among this key high-risk group did not begin to climb until about 10 years later, in 2008. From 2008 to 2017, a sharp increase in the annual number of newly identified cases among MSM has been observed (Fig. 34.7). As of the end of 2017, a cumulative total of 17,306 HIV/AIDS cases among MSM in Guangdong had been identified.

Due to enduring stigma and discrimination against MSM in China, it is thought that many MSM diagnosed with HIV report their route of transmission as heterosexual contact, blood transfusion, or unknown, resulting in underestimation of the true HIV prevalence among this group. Furthermore, many have never before received HIV testing due to concerns over privacy and confidentiality as well as other important barriers. Therefore, it is likely that many MSM have HIV infection and still do not know their status, further causing underestimation of the HIV

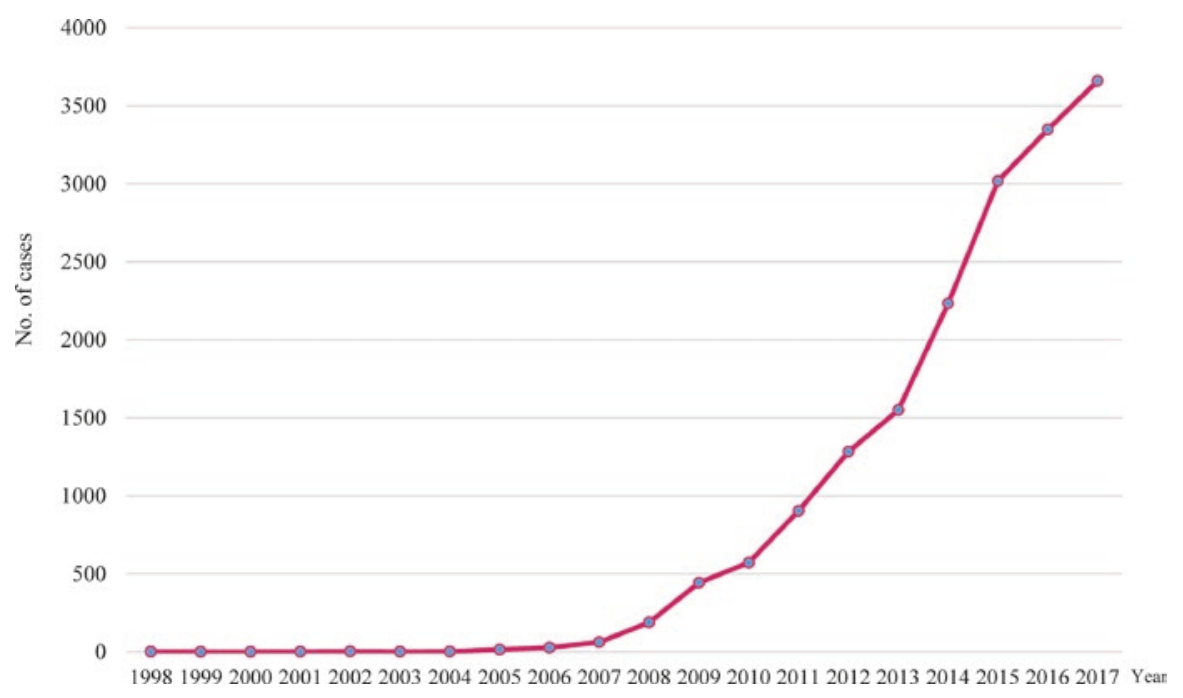

Fig. 34.7 Annual number of HIV cases among MSM in Guangdong province, 1998-2017 
Table 34.5 HIV prevalence among MSM based on sentinel surveillance data in Guangdong, 2002-2017

\begin{tabular}{l|l|l|l|l|l|l|l|l}
\hline Year & $\begin{array}{l}\text { Guangzhou } \\
\%\end{array}$ & $\begin{array}{l}\text { Shenzhen } \\
\%\end{array}$ & $\begin{array}{l}\text { Foshan } \\
\%\end{array}$ & $\begin{array}{l}\text { Zhongshan } \\
\%\end{array}$ & $\begin{array}{l}\text { Dongguan } \\
\%\end{array}$ & $\begin{array}{l}\text { Jiangmen } \\
\%\end{array}$ & $\begin{array}{l}\text { Zhanjiang } \\
\%\end{array}$ & $\begin{array}{l}\text { Zhuhai } \\
\%\end{array}$ \\
\hline 2002 & - & 0.91 & - & - & - & - & - & - \\
\hline 2003 & 1.71 & - & - & - & - & - & - & - \\
\hline 2004 & - & 1.53 & - & - & - & - & - & - \\
\hline 2005 & 0.74 & 1.67 & - & - & - & - & - & - \\
\hline 2006 & 1.71 & 2.48 & - & - & - & - & - & - \\
\hline 2007 & - & 3.90 & - & - & - & - & - & - \\
\hline 2008 & 5.20 & 7.90 & - & - & - & - & - & - \\
\hline 2009 & 4.00 & 5.80 & 2.90 & - & - & - & - & - \\
\hline 2010 & 7.29 & 11.19 & 9.52 & 10.00 & 10.50 & - & - & - \\
\hline 2011 & 9.25 & 13.00 & 10.20 & 12.60 & 11.30 & 6.80 & - & - \\
\hline 2012 & 10.00 & 12.30 & 13.10 & 15.70 & 22.90 & 7.40 & - & - \\
\hline 2013 & 10.94 & 10.80 & 12.72 & 11.93 & 17.56 & 6.65 & - & - \\
\hline 2014 & 12.34 & 12.17 & 12.21 & 12.35 & 17.25 & 7.30 & 6.57 & - \\
\hline 2015 & 11.00 & 9.00 & 13.83 & 12.00 & 14.73 & 5.67 & 5.71 & 8.13 \\
\hline 2016 & 8.75 & 7.75 & 13.23 & 15.60 & 12.98 & 5.99 & 8.17 & 9.45 \\
\hline 2017 & 3.76 & 8.25 & 12.26 & 13.20 & 11.54 & 6.98 & 3.08 & 7.39 \\
\hline & & & & & & & &
\end{tabular}

epidemic among MSM in Guangdong. Nevertheless, the steep increase in cases that are reported is cause for serious concern.

Since MSM tend to be "hidden" because of persistent stigma and discrimination, epidemiological survey data have historically been somewhat scarce. However, as of 2017, a total of eight sentinel surveillance sites existed among MSM in the Pearl River Delta area. Surveys and reports from these sentinel sites suggest that HIV prevalence among MSM has been increasing substantially (Table 34.5 and Fig. 34.8).

A study among MSM in Shenzhen showed that HIV prevalence increased from $1.7 \%$ in 2005 to $9 \%$ in 2015 (Cai et al. 2017). Another study also conducted in Shenzhen, found HIV prevalence among MSM to be12\% (Cai et al. 2017). A similar study conducted in Guangzhou, targeting the MSM who used HIV self-testing, found HIV prevalence among this subgroup to be $4.5 \%$ (Zhong et al. 2017). However, the lack of data from the eastern and western parts of the province leaves the spread of the epidemic for MSM in these areas largely unmapped.

\subsubsection{The Response and the Epidemiological Situation for MSM}

To reduce transmission of HIV through male-male sexual contact, behavioral intervention programs, particularly condom use promotion and testing campaigns, have been conducted. However, this population has been difficult to reach via governmentdriven intervention programs. CBO- and NGO-led interventions for MSM have only been available in Guangzhou and Shenzhen prior to 2008. After 2008, more and more NGOs have been involved in intervention programs targeting MSM. In 2017, of 216,270 MSM were covered by intervention programs and a total of nearly 42,000 were tested for HIV. However, most of the intervention programs were conducted in the Pearl River Delta Region and some of the western cities including 


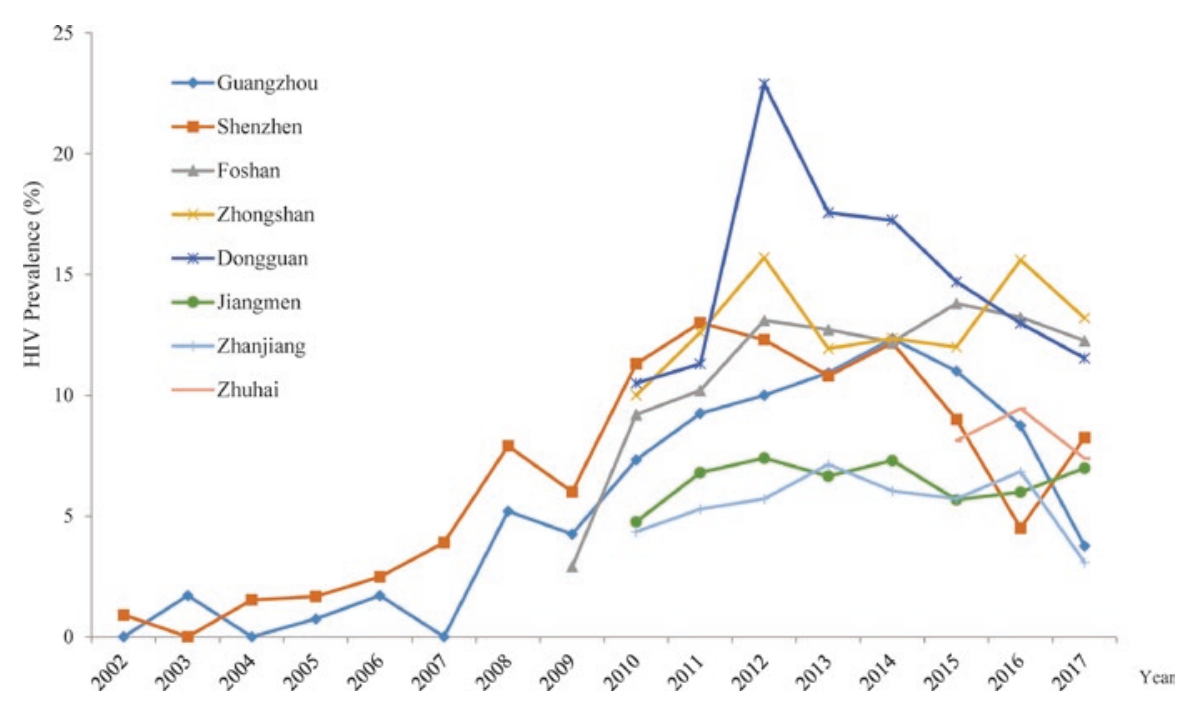

Fig. 34.8 HIV prevalence among MSM based on sentinel surveillance data from eight Guangdong cities, 2002-2017

Zhanjiang and Yunfu, and coverage of HIV prevention interventions for MSM in eastern Guangdong is very poor (see Chap. 8 for more information).

\subsubsection{Women}

\subsubsection{HIV Case Reports Among Women}

From 1997 to 2017, a total of 15,488 newly diagnosed HIV cases were reported among females in Guangdong province. Overall, newly diagnosed female PLWH tended to be in their $20 \mathrm{~s}$ or $30 \mathrm{~s}$ (57\%), residents of Guangdong (62\%), and reside in the central region of the province (63\%; Table 34.6). Over time, newly-diagnosed female PLWH tended to be older-only $2 \%$ were 50 years of age or older from 1997 to 2002 , whereas $30 \%$ were 50 or older from 2013 to 2017 . Furthermore, over the years, larger and larger proportions of female FSW were non-residents of Guangdong. Overall, the most common mode of transmission was heterosexual contact, with a notable exception—from 1999 to 2001 the most common mode of transmission was injection drug use (Table 34.6 and Fig. 34.9). In 2017, more than $90 \%$ of HIV cases among females were acquired via heterosexual contact (see Chap. 7 for more information).

\subsubsection{HIV Surveillance Among Pregnant Women}

HIV sentinel surveillance sampling pregnant women was initiated in 1999 in Guangzhou and Dongguan, and in Jiangmen in 2002. By 2010, the number of sentinel sites among pregnant women increased from these 3 to a total of 19 . The aggregated 
Table 34.6 Characteristics of HIV-positive women diagnosed in Guangdong province from 1997 to 2017 and in successive 5-year periods

\begin{tabular}{|c|c|c|c|c|c|}
\hline Characteristics & $\begin{array}{l}1997-2017 \\
N(\%)\end{array}$ & $\begin{array}{l}1997-2002 \\
N(\%)\end{array}$ & $\begin{array}{l}2003-2007 \\
N(\%)\end{array}$ & $\begin{array}{l}2008-2012 \\
N(\%)\end{array}$ & $\begin{array}{l}2013-2017 \\
N(\%)\end{array}$ \\
\hline \multicolumn{6}{|l|}{ Age at diagnosis, years } \\
\hline$<15$ & $233(1.5)$ & $2(1.5)$ & $30(1.8)$ & $116(1.9)$ & $85(1.1)$ \\
\hline $15-19$ & $417(2.7)$ & $4(2.9)$ & $41(2.5)$ & $169(2.8)$ & 203 (2.6) \\
\hline $20-29$ & $4479(28.9)$ & $83(60.6)$ & $721(44.3)$ & $2025(33.8)$ & $1650(21.3)$ \\
\hline $30-39$ & $4318(27.9)$ & $40(29.2)$ & $587(36.1)$ & $1874(31.3)$ & $1817(23.5)$ \\
\hline $40-49$ & $2700(17.4)$ & $3(2.2)$ & $132(8.1)$ & $899(15.0)$ & $1666(21.5)$ \\
\hline$\geq 50$ & 3339 (21.6) & $3(2.2)$ & $115(7.1)$ & $904(15.1)$ & $2317(29.9)$ \\
\hline Unknown & $2(<0.1)$ & $2(1.5)$ & $0(0.0)$ & $0(0.0)$ & $0(0.0)$ \\
\hline \multicolumn{6}{|l|}{ Transmission route } \\
\hline Heterosexual contact & $13,617(87.9)$ & $47(34.3)$ & $1066(65.6)$ & $5173(86.4)$ & $7331(94.7)$ \\
\hline Injection drug use & $1055(6.8)$ & 68 (49.6) & $355(21.8)$ & $422(7.0)$ & $210(2.7)$ \\
\hline Blood products & $146(0.9)$ & $8(5.8)$ & $32(2.0)$ & $106(1.8)$ & $0(0.0)$ \\
\hline Mother-to-child & $206(1.3)$ & $0(0.0)$ & $26(1.6)$ & $111(1.9)$ & $69(0.9)$ \\
\hline Not classified & $464(3.0)$ & $14(10.2)$ & $147(9.0)$ & $175(2.9)$ & $128(1.7)$ \\
\hline \multicolumn{6}{|l|}{ Guangdong residency } \\
\hline Resident & 9664 (62.4) & $97(70.8)$ & 1057 (65.0) & 3859 (64.5) & $4651(60.1)$ \\
\hline Non-resident & $5744(37.1)$ & 38 (27.7) & $491(30.2)$ & $2128(35.5)$ & 3087 (39.9) \\
\hline Unknown & $80(0.5)$ & $2(1.5)$ & $78(4.8)$ & $0(0.0)$ & $0(0.0)$ \\
\hline \multicolumn{6}{|l|}{ Region in Guangdong } \\
\hline Central & $9751(63.0)$ & $117(85.4)$ & $1220(75.0)$ & $3779(63.1)$ & 4635 (59.9) \\
\hline West & $1640(10.6)$ & $12(8.8)$ & $93(5.7)$ & $560(9.4)$ & 975 (12.6) \\
\hline East & 4097 (26.5) & $8(5.8)$ & $313(19.2)$ & $1648(27.5)$ & $2128(27.5)$ \\
\hline
\end{tabular}

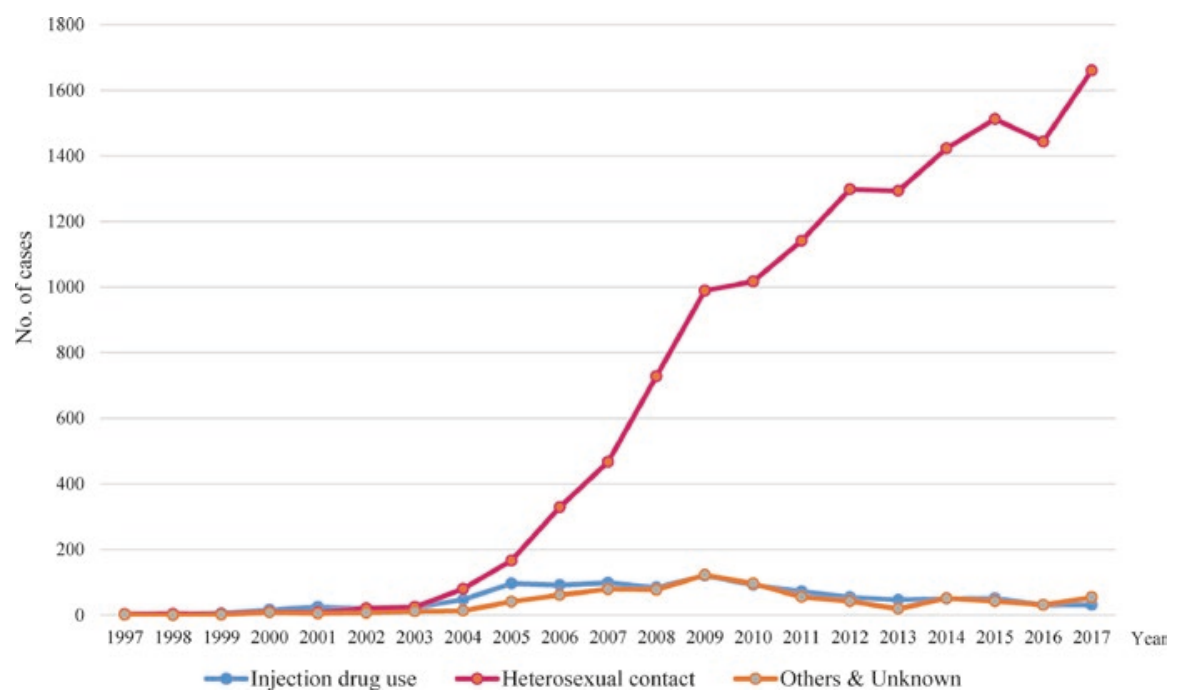

Fig. 34.9 HIV prevalence among women in Guangdong stratified by transmission route, 1997-2017 
HIV prevalence among pregnant women tested at these sites was lower than $0.1 \%$ throughout the period. In 2017, HIV infections were detected in three of the 19 sentinel sites, with the highest prevalence observed to be $0.3 \%$ at one site.

\subsubsection{The Syphilis Epidemic Among Women}

As the presence of syphilis infection both increases the susceptibility and transmissibility of HIV infection, the dramatic rise in syphilis incidence and prevalence among women in China is a serious issue. A study conducted in six Guangdong cities in 2004 and 2005 showed that the prevalence of syphilis among pregnant women across 23 hospitals ranged from $0.4 \%$ to $0.9 \%$ (Chen et al. 2006). Another study found that latent syphilis incidence among women of childbearing age (1549) in Guangdong province increased from 17.4 per 100,000 residents in 2005 to 48.8 per 100,000 in 2010 (Ren et al. 2012). Finally, a study of Guangdong's cities from 2012 to 2013 found that 3,281,321 (93\%) pregnant women had received HIV testing and 2,918,914 (83\%) had received syphilis testing, and that the prevalence of HIV and syphilis were 1.8 per 100,000 and 14.2 per 100,000, respectively (Tang et al. 2015) (see Chap. 3 for more information).

\subsubsection{Response to HIV Among Women}

A prevention of mother-to-child transmission (PMTCT) intervention program was initiated in 2004, initially covering three counties. It expanded to cover all counties by 2017, providing free screening for pregnant women and intervention for those who were diagnosed with HIV infection. However, in counties not covered by the program, women often paid for the testing. In total, over $99.8 \%$ of the pregnant women in Guangdong province were screened for HIV in 2017 (see Chap. 15 for more information).

\subsubsection{The Migrant Population}

\subsubsection{Migrants Are at High Risk and Vulnerable}

Guangdong is the most populous province with the largest migrant population in China. This floating population in Guangdong has been estimated at above 30 million. A majority of male migrant workers are employed in industry and construction, while most female migrant workers are employed in industry and service establishments such as hotels, restaurants, and entertainment venues. Studies have shown that the migrant population tends to have lower educational attainment, lower income, and lower access to health services compared to permanent residents who hold a hukou.

Most migrants are sexually active and are vulnerable to HIV and other STIs. A study in Guangdong found that the HIV awareness rate among the migrant population was only $49 \%$, that $8 \%$ of the participants had extramarital sex in the last year and that only $72 \%$ of them used condoms in their most recent extramarital sexual 
contact (Liu et al. 2009). A study in Foshan city showed that HIV awareness and risk behavior varied for different occupations among the migrant population. HIV awareness was particularly low among workers in the entertainment, restaurant, and construction industries. The study also showed that $31 \%$ had engaged in commercial sex and 9\% reported non-commercial casual sex in the last year (Chen et al. 2011). A similar study conducted in Shenzhen found that $4 \%$ of surveyed migrants had taken part in commercial sex and only $36 \%$ of them reported consistent condom use (Sun et al. 2017).

An exaggerated vulnerability is experienced by individuals in dual-risk populations, such as migrants who are MSM. In a study of migration patterns among MSM, Guangdong had the highest migrant inflow ratios-migrant MSM were moving into Guangdong from areas of higher HIV prevalence among the broader MSM population (Mi et al. 2016). A study conducted in Guangzhou showed that migrant MSM, compared to local MSM, have higher odds of reporting unprotected anal intercourse, having multiple male sexual partners, and lower rates of condom use (Wu et al. 2016).

\subsubsection{Surveillance Among Migrant Workers}

Because migrants were significantly over-represented among HIV case reports, six sentinel surveillance sites were set up in the Pearl River Delta region, where the migrant population is most concentrated, beginning in 2010. The annual HIV prevalence among migrants sampled at the six sites overall was $0.04 \%, 0.14 \%, 0.12 \%$, $0.08 \%, 0.17 \%, 0.04 \%, 0.04 \%$, and $0.17 \%$ in the years from 2010 to 2017, respectively.

A cross-sectional study in Zhuhai found that $75 \%$ of PLWH were migrants (Li et al. 2018). A similar study in Dongguan found that the proportion of migrants among PLWH rose from 52\% in 2010 to $71 \%$ in 2015 (Li et al. 2016). A study conducted in Zhongshan in 2010 estimated an HIV prevalence of $0.13 \%$ among the migrant population (Tan et al. 2011). A cross-sectional study conducted in three medium-sized Guangdong cities with large floating populations found the prevalence of HIV and syphilis were $0.17 \%$ and $1.31 \%$, respectively (Fu et al. 2013).

\subsection{Conclusion}

With sudden and rapid trade liberalization and economic development as a backdrop, China's HIV epidemic has taken a somewhat unique course in Guangdong province. Although slow to get started, with only 500 cases identified cumulatively as of 2003, HIV prevalence increased rapidly, particularly among high-risk groups. Guangdong must redouble its efforts in prevention and expand testing, treatment, and care if it is to bring its HIV epidemic under control.

Acknowledgments Authors gratefully acknowledge Jennifer M. McGoogan, who provided input and assisted with editing. 


\section{References}

Cai Y, Song Y, Hong F. Joinpoint regression analysis on trends of syphilis/HIV prevalence among men who have sex with men in Shenzhen. Chin J AIDS STD. 2017;23(1):33-5.

Chen Y, Sun X, Chen W, Wan X, Wu L. Analysis of syphilis epidemiology in Guangdong pregnant women. S Chin J DermVenereol. 2006;13(4):263-5.

Chen S, Liang Z, Gong Y, Sui D, Zhu Z. Mobility among floating population of different occupations and their AIDS knowledge and risk behaviors. S Chin J Prev Med. 2011;37(2):1-5.

Deng Z, Liu J. Status of syphilis infection and influence factors among male patients of the STD clinic in Dongguan City from 2010 to 2016. Chin J AIDS STD. 2018;24(4):383-6.

Fang X, Liao H, Lin X. Syphilis and HIV infection status in outpatients with sexually transmitted diseases in Shantou, 2004-2011. Chin J AIDS STD. 2012;18(10):664-6.

Fu X, Lin P, Li Y, Wang T, Zhu J, Liang Z. Investigation on HIV/AIDS risk behaviors and HIV infection status among the floating population in different locations in three cities in Guangdong Province. Chin J Dis Control Prev. 2013;17(3):226-9.

Fu X, Wang B, Li Y, Yang C, Lin G, Peng L. Prevalence of HIV and sexually transmitted diseases as well as related associated risk factors among middle/low-level female sex workers in a city in Guangdong province. Chin J Epidemiol. 2014;35(5):510-3.

Gong X, Ye S, Zhang J, Zhang G, Shao C, Liang G, et al. Epidemiological situation of sexually transmitted diseases in China: from 1991 to 2001. Chin J Dermatol. 2002;35(3):178-82.

Lau JT, Thomas J. Risk behaviors of Hong Kong male residents traveling to mainland China: a potential bridge population for HIV infection. AIDS Care. 2001;13(1):71-81.

Li Y, Li W, Lin P, Mai R, Liu Y, Yang L, et al. A study of population size estimation of female sex workers in a city in Guangdong Province. S Chin J Prev Med. 2006;32(4):18-20.

Li Y, Detels R, Lin P, Fu X, Deng Z, Liu Y, et al. Prevalence of HIV and STIs and associated risk factors among female sex workers in Guangdong Province, China. J Acquir Immune Defic Syndr. 2010;53(Suppl 1):S48-53. https://doi.org/10.1097/QAI.0b013e3181c7d72f.

Li Y, Detels R, Lin P, Fu X, Deng Z, Liu Y, et al. Difference in risk behaviors and STD prevalence between street-based and establishment-based FSWs in Guangdong Province, China. AIDS Behav. 2012;16(4):943-51. https://doi.org/10.1007/s10461-011-0102-0.

Li T, Wen J, Zhu K, Zhou G, Qin S, Zheng R, et al. Investigation on sexual behavior safety and syphilis infection in recreational places in Haizhu District, Guangzhou. J Dermatol Venereol. 2016;23(1):57-9.

Li W, Zhou Y, Huang S, Yao G, Li X, Du M. Analysis of epidemic characteristics of AIDS in Zhuhai City in 2016. Med Inf. 2018;31(3):123-5.

Liang Z. Foreign investment, economic growth, and temporary migration: the case of Shenzhen Special Economic Zone, China. Dev Soc. 1999;28(1):115-37.

Lin P, Wang M, Li Y, Zhang Q. Comparison of HIV prevalence and its correlates between the community-based and the detoxification center-based drug users. Mod Prev Med. 2013;40:463-6.

Liu Y, Lin P, Fu X, Long Q, Wang Y, Yang F, et al. Analysis on the HIV/AIDS knowledge, behavior and influence factors of floating population in Guangdong Province. S Chin J Prev Med. 2009;35(6):23-7.

Mi G, Ma B, Kleinman N, Li Z, Fuller S, Bulterys M, et al. Hidden and mobile: a web-based study of migration patterns of men who have sex with men in China. Clin Infect Dis. 2016;62(11):1443-7. https://doi.org/10.1093/cid/ciw167.

Ren X, Yang L, Chen Y, Liu F, Hong X, Yang B. Epidemiological trends of the secondary and latent syphilis among women of childbearing age in Guangdong Province of China: from 2005 to 2010. Chin J Infect Control. 2012;11(3):174-7.

Shen H, Zou H, Huang S, Liu F, Zhao P, Chen L, et al. Depression and HIV risk behaviors among female sex workers in Guangdong, China: a multicenter cross-sectional study. Biomed Res Int. 2016;2016:6986173. https://doi.org/10.1155/2016/6986173. 
Song W, Liang G, Xia Q. Epidemiology analysis on venereal disease in China in 1977-1993. Dis Surveil. 1995;10(2):57-61.

Spence JD. The search for modern China. New York: WW Norton \& Company; 1990.

Statistics Bureau of Guangdong Province. Guangdong statistical yearbook 2017. Beijing: China Statistics Press; 2017.

Sun Q, Fang F, Zhou Z, Gan L, Zheng L, Tu Y, et al. Factors influencing utilization of HIV voluntary counseling and testing services among migrant population in Baoan district. Chin J AIDS STD. 2017;23(1):44-7.

Tan X, Huang S, Lu H, Zhu Z, Huang L, Xu Y, et al. Survey of HIV infection among STD outpatients from 2003 to 2007 in Jiangmen. J Trop Med. 2008;8(12):1257-8.

Tan Y, Wang T, Li L, Wang M, Li X, He H, et al. Survey on prevalence of HIV and syphilis among migrants in Zhongshan in 2010. Pract Prev Med. 2011;18(5):803-5.

Tang L, Zhao Q, Li B. Analysis the situation of HIV, syphilis, and HBV testing services among pregnant women in Guangdong, 2012-2013. Chin J AIDS STD. 2015;21(9):762-5.

Tucker JD, Cohen MS. China's syphilis epidemic: epidemiology, proximate determinants of spread, and control responses. Curr Opin Infect Dis. 2011;24:50-5.

Wang C, Yang L, Yang B, Shen S. Prevalence of syphilis and gonorrhea in Guangdong province, 1995 to 2010. Chin J Public Health. 2013;29(3):423-5.

Wu J, Wu H, Li P, Lu C. HIV/STIs risks between migrant MSM and local MSM: a cross-sectional comparison study in China. PeerJ. 2016;4:e2169. https://doi.org/10.7717/peerj.2169.

Zhang H, Huang H. Survey and analysis on STDs of 1286 female sex workers in Jiangmen City of Guangdong Province. S Chin J Derm Venereol. 2012;19(3):178-81.

Zhang S, Peng H, Chen F, Chen F, Huang X. The analysis of STD infection among male STD outpatients in Huizhou from 2008 to 2012. Diagnos Ther J Derm Venereol. 2013;20(3):211-2.

Zhao P, Huang S, Liu F, Ren X, Chen L, Shen H, et al. A special survey of comprehensive syphilis prevention and control in Guangdong province. Chin J AIDS STD. 2016;22(6):451-4.

Zhao P, Shen H, Huang S, Wang C, Deng Z, Li Z, et al. Analysis on the status and related factors of high-risk behaviors of sexually transmitted diseases/HIV among clients of female sex workers in Guangdong Province. Chin J Dis Control. 2018;22(1):100-3.

Zhong F, Tang W, Cheng W, Lin P, Wu Q, Cai Y, et al. Acceptability and feasibility of a socialentrepreneurship model to promote HIV self-testing and linkage to care among men who have sex with men. HIV Med. 2017;18(5):376-82. https://doi.org/10.1111/hiv.12437. 